\title{
A COMPARATIVE STUDY OF WATERFRONT USE AS ECOSYSTEM SERVICES IN SAINT-PETERSBURG AND OSAKA
}

\author{
Ikujiro Wakai \\ Osaka Sangyo University; 3-1-1, Nakagaito, Daito-Shi, Osaka, 574-8530, Japan \\ wakai@due.osaka-sandai.ac.jp
}

\begin{abstract}
Based on the concept of ecosystem services, this study aimed to clarify a direction for the use of precious waterfronts remaining in congested large modern cities. Rivers and canals of Saint Petersburg, Russia and Osaka, Japan were selected as the study subjects. The actual status of waterfront use in both cities was examined through qualitative analyses from the viewpoint of ecosystem services. As a result, it was revealed that there were differences between the two cities in their use of waterfronts, and that the creation of waterfronts with high environmental value based on the consideration of ecosystem services has a positive effect on tourism, land price, and health.
\end{abstract}

\section{Keywords}

Use of waterfronts, ecosystem services, Saint Petersburg, Osaka, rivers, canals

\section{Introduction}

Today's cities are becoming congested. Cities are characterized strongly by the fact that they use land vertically, as opposed to rural regions which use land horizontally. This clear distinction in land use is brought by major advances in modern civil and building engineering technologies. Such progress has enabled urban buildings to be both extremely large and tall, and encouraged the vertical use of small urban spaces, i.e. utilization of space high into the air. The causes also lie in the fact that urban land is not replaceable, is high in price, and difficult to obtain in the midst of over-concentrated and highlydeveloped urban functions, resulting in the need for effective vertical use. Thus urban spaces become smaller resulting in a more closed feeling every year.

In such closed urban environments, rivers, canals and parks provide open space. Until now, parks have been considered in urban planning as they were regarded as a necessary facility from the standpoint of fire protection and health. On the contrary, however rivers and canals were often regarded as a means of waterway transport and viewed in terms of flooding. In fact, the open spaced rives and canals remaining in cities today flourished as waterway transport systems for daily commodities in the old days and industrial raw materials and goods after the Industrial Revolution. However, with the advancement of large- scale industrial production and cargo shipment, the distribution function needed for commerce and trade as well as industrial production were transferred to the city periphery or neighboring locations, and the role of such urban waterway transport was reduced. Therefore, some urban rivers and canals were filled and used as parks and roads.

With a good amount of vegetation and organized open space, urban parks have high environmental and health value, providing city dwellers and workers with comfort and relaxation. Likewise, the waterfront spaces of rivers and canals in cities also represent a valuable and precious urban space consisting of water in an open continuous linear form, comparable to parks. Rivers and canals feature expansive ecosystems, unlike urban parks which are limited in this regard, as they comprise ecosystems which link to watersheds or the sea.

It is now time to review rivers and canals for city dwellers, workers and visitors, in order to further enrich urban ecosystems by enhancing their environmental and health value, as a legacy of open spaces with rich ecosystems.

\section{Study objectives}

Urban waterfront spaces such as rivers and canals are valuable assets which provide natural elements to congested cities and their open atmosphere has the potential to further increase environmental 
and health value. Thus such waterfront spaces have been regarded as important for city planning in terms of maintenance and the creation of a pleasant urban landscape. They have been primarily considered as a backdrop of 'dry' inorganic building blocks alongside and to harmonize with the form, height and colour of the buildings, or as a formation element of an urban landscape to supplement a lack of expansiveness and depth of urban space. In other words, waterfront spaces were thought to be necessary in order to create scenes which soften a 'dry' inorganic urban landscape, that is to say, places for landscape interaction between the ecosystems of waterfronts and humankind. This type of urban landscape formation, although contributing to the improvement of environmental and health values, simply creates limited value which lacks diversity. Meanwhile what is required more than ever for modern cities is to create various valuable services of nature-rich waterfront spaces, thereby enhancing the attractiveness of cities for citizens and visitors who have a greater diversity of values.

Based on an awareness of these issues together with the conventional view concerning urban waterfronts, this study aimed to clarify a direction for the urban waterfront spaces of this century; through introduction of a concept of ecosystem services which views the interaction between ecosystems and humankind in an integrated manner, comparison of ecosystem services between similar cities, and review of the environmental and health value of waterfront spaces, in order to provide more depth and options. As subjects of the study, the cities of Saint Petersburg and Osaka were selected for their similarities in natural topography and conditions of location.

\section{Past studies}

It was during the 1980s when the decline of large cities began in the United States, that urban waterfront spaces became the focus of attention as a 'third urban space' which was not the area of a continent or body of water, but an area where both of these overlap. At that time, studies concerning the use of urban waterfronts mainly concerned the reconstruction of pleasant cityscapes and development methods for their formation elements with changes in land use. These major urban developments resulted from the renewal and innovation of urban functions through urban planning and reorganisation of land use, including urban redevelopment by reconstructing decrepit existing buildings, construction of new buildings on sites where stagnant secondary industry had been located, and revitalisation of old harbour districts with obsolete distribution functions. As the urban planning and reorganisation of land use primarily aimed for the renewal and innovation of urban functions while at the same time creating a new cityscape in waterfront spaces, they succeeded in raising landscape functions in some areas, but did not lead to improvement of the waterfront function of the city as a whole, nor dramatically enhance the attractiveness of waterfront spaces.

In Japan, domestic heavy industry also began to decline in the 1980s, due to the industrial advancement of developing countries, and effective use of old factory sites became a social problem. Although the regeneration of urban waterfronts drew attention, a large part of the development plan targeted the creation of venues for recreation and tourism within the city, while focusing on development methods concerning urban planning and land use. The development methods included expansion of urban facilities by responding to the needs of the time, such as water parks to raise city attractiveness and high-rise buildings and cultural facilities integrated with waterfronts. In other words, the regeneration of waterfront spaces was to develop urban facilities integrated with waterfronts through the creation of long-awaited urban spaces with high amenity and meeting the demands of tourism, while raising the usage value of land having a waterfront as its backdrop, and ultimately anticipating an increase of real estate. This contributed to a quantitative expansion of urban amenities mainly related to waterfront spaces, however it was not sufficient in terms of the interaction between nature and humankind.

Such regeneration of waterfront spaces resulted in the creation of 'dry' inorganic spaces and failed to create truly pleasant waterfronts, as its emphasis was placed on the creation of cityscape function. It will be necessary in the future for studies concerning the use of waterfront spaces to cover not only the conventional scope of study, which focuses on the creation of cityscape function, but to extend the creation and development of high-quality waterfront spaces which can express multifaceted ecosystem functions and services, rather than through a single approach, by focusing on the diversity of interaction between the ecosystem and humankind.

\section{The ecosystem services concept}

From ancient times, humankind has been a constituent of the ecosystem and benefited tremendously from it. At the same time, humankind has effected the ecosystem while modifying and altering it in some respects, in other words, humankind and the ecosystem have continued their interactive relationship. Ecosystem services are the benefits by which such relationship was reviewed from an economic perspective.

Ecosystem services are the concept proposed by the United Nations as shown in Figure 1. The Millennium Ecosystem Assessment called for by the United Nations relates ecosystem services to the welfare of humankind in order to improve the benefit of humanity. This study also quotes the UN's concept of ecosystem services. 
Ecosystem services proposed by the UN are categorized by the following four services:

Firstly, Provisioning Services; this is to provide materials concerning human activities such as livelihood and industry, including water, food, fuel, fibre, chemicals and genetic resources. They are the services viewed from the perspective of the utility value of natural resources.

Secondly, Cultural Services; this is to utilize natural resources from the ecosystem indirectly and as a background element, including spiritual value, ideas, recreation, aesthetic benefits, education, benefits as a collective, and symbolic benefits. They have favourable influences on the human spirit and intellectual activities, and are based on rare and unique values.

Thirdly, Regulating Services; this is to mitigate the risk effect that nature has on people, including the control of climate, disease and flood, and detoxification. Such risk increases in reverse, in proportion to the degree of excessive human activity and the progress of overdevelopment.

Fourthly, Supporting Services; this is the foundation which supports the ecosystem, including soil formation, nutrient cycling and primary production. Their quantitative and qualitative soundness has a great influence on the productivity and growth of the tropical natural environment.

In this study, the multi-faceted nature of the use of urban waterfront spaces was considered based on the concept of ecosystem services.

5. Overview of study subjects; Saint Petersburg and Osaka

The cities of Saint Petersburg and Osaka selected as the study subjects established a sister-city relationship on 16th August, 1979, and since have actively promoted economic and cultural exchanges. Saint Petersburg and Osaka have populations of approximately 4.93 million (2011) and 2.68 million (2013) respectively, meaning that the former has about 1.8 times the latter. With respect to the city areas, Saint Petersburg is $1,400 \mathrm{~km}^{2}$ and Osaka $221 \mathrm{~km}^{2}$, meaning that the former has an area about 6.3 times that of the latter (Fig. 2).

Despite the above different social conditions, the two cities are similar in natural conditions and both have a history as harbour cities. Regarding natural conditions, Saint Petersburg is situated in a delta region at the mouth of the Neva River originating in Lake Ladoga, the largest lake in Europe, with Neva Bay to its west. Osaka is situated in a delta region at the mouth of the Yodo River originating in Lake Biwa, the largest lake in Japan, with Osaka Bay to its west. Both the Neva River and Yodo River are $74 \mathrm{~km}$ long, and their natural conditions are therefore similar (Fig. 2). In addition, both cities have a prevailing strong westerly wind in winter, due to the relative position of the bay and city.

Thus both are harbour cities located at the mouth of rivers. Saint Petersburg was founded as the imperial capital by Tsar Peter the Great in the early 18 th century, and has since flourished as a harbour city through overseas trade. Osaka developed in the 17 th century and further flourished as a harbour city serving as the base port for water routes for domestic trade. Experiencing high waves caused by westerly winds prevailing in winter due to their locations at the mouth of rivers, it was difficult for the cities to dredge their harbours to secure the water depth to counter the frequent berthing and unberthing of ships and

\begin{tabular}{|c|c|c|}
\hline $\begin{array}{l}\text { Provisioning Services } \\
\text { Benefits obtained from } \\
\text { the ecosystem } \\
\text { Food } \\
\text { Water } \\
\text { Fuel } \\
\text { Fibre } \\
\text { Chemicals } \\
\text { Genetic resources }\end{array}$ & $\begin{array}{l}\text { Regulating Services } \\
\text { Benefits obtained from } \\
\text { regulation of the } \\
\text { ecosystem processes } \\
\text { Climate regulation } \\
\text { Disease control } \\
\text { Flood control } \\
\text { Detoxification }\end{array}$ & $\begin{array}{l}\text { Cultural Services } \\
\text { Non-material benefits } \\
\text { obtained from the } \\
\text { ecosystem } \\
\text { Spiritual value } \\
\text { Recreation } \\
\text { Aesthetic benefits } \\
\text { Ideas } \\
\text { Education } \\
\text { Benefits as a collective } \\
\text { Symbolic benefits }\end{array}$ \\
\hline \multicolumn{3}{|c|}{ Supporting Services } \\
\hline Soil formatio & \multicolumn{2}{|l|}{ Nutrient cycling Prin } \\
\hline
\end{tabular}

Note: Cited from Seibutsu Tayosei wa Naze Taisetsu ka (Why Is Biodiversity Important?), edited by Toshitaka Hidaka (2010)

Fig. 1. Ecosystem Services 


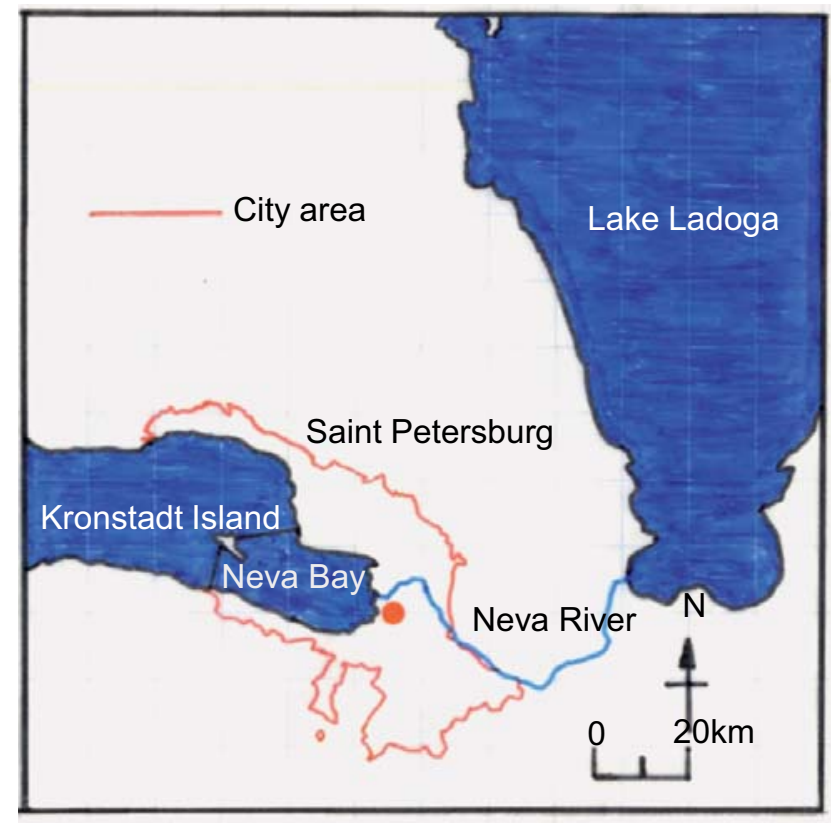

Fig. 2. Location of Saint Petersburg and Osaka

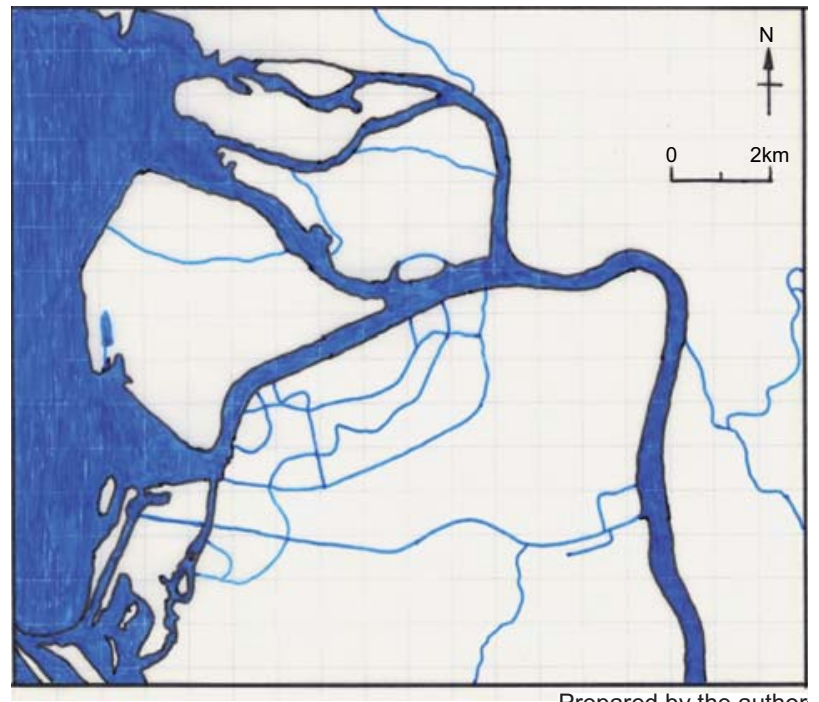

Fig. 3 Main river and canal network in Saint Petersburg

the deposit of a large amount of sediment from the rivers. Therefore it was disadvantageous for them to build harbours at the mouth of rivers, and instead harbours were built upriver. To respond to the increasing demand for water transportation, canals were built to connect these rivers, thereby providing better access to the city centres. The current river and canal networks are as follows (Figs. 3 and 4). Some of the canals in Osaka were filled and became roads in order to relieve the traffic congestion that was worsened by motorization during the 1960s (Fig. 4). The river and canal networks which once played a major role for water transportation in the two cities are now drawing attention as valuable

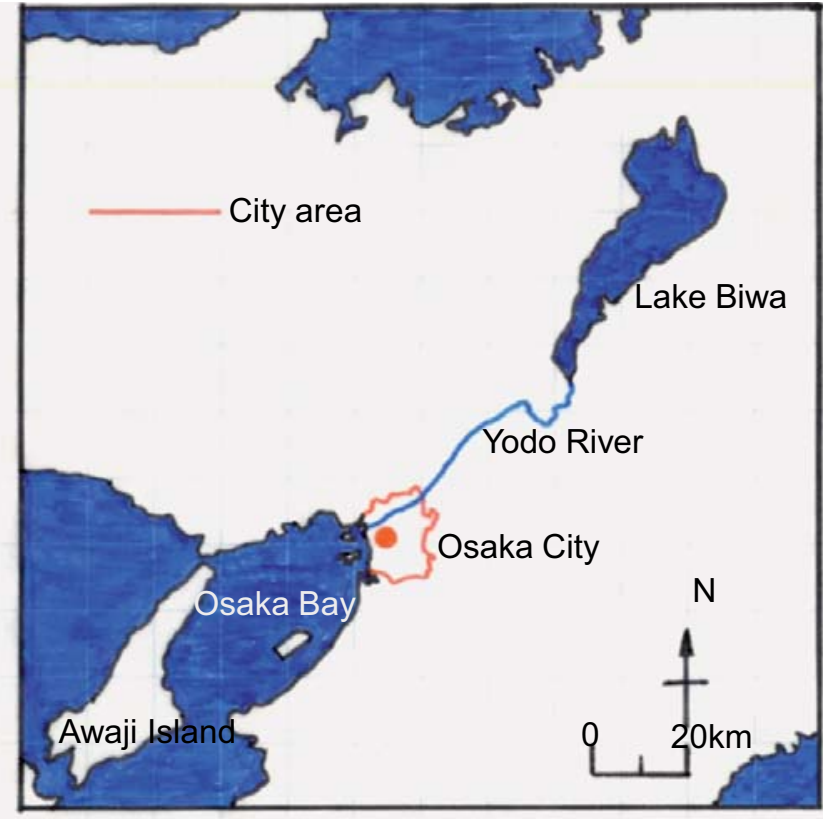

Prepared by the author

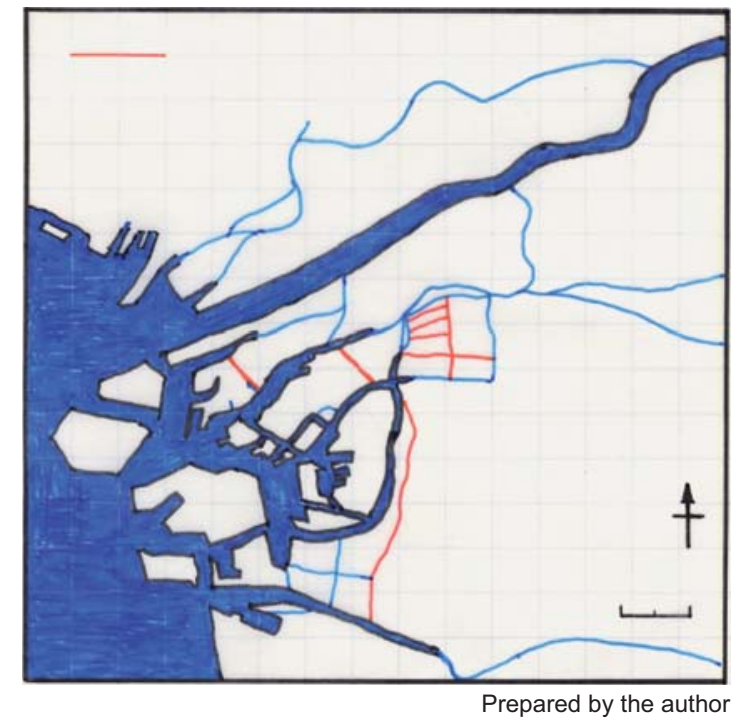

Fig. 4 Main river and canal network in Osaka

waterfront spaces. Further, it is anticipated that such spaces will generate diversity for their use from the additional perspective of ecosystem services.

\section{Consideration of waterfront space use by the sister cities}

A waterfront is an attractive space which allows us to have contact with nature i.e. water and living creatures. Therefore, for a large densely built city of today, whether it has a waterfront space or not determines the degree of its attractiveness. Being sister cities and similar in terms of location, both Saint Petersburg and Osaka are metropolises blessed with such waterfront spaces consisting of rivers and canals spread through their city centres. 
Presently, these spaces in both cities appear to be regarded as resources for tourism to attract visitors. However, although they serve as important assets for tourism in large cities, it is also necessary to develop them as high-quality symbiotic spaces between waterfronts and humankind, by re-examining them as one of the urban resources benefitting those who live there. To this end, introduction of the ecosystem service concept becomes effective. In this study, representative examples of waterfront use in Saint Petersburg and Osaka are considered from the viewpoint of ecosystem services in four locations; the tourism district, city centre, the district near the mouth of the river, and the mouth of the river.

\subsection{Waterfront use in the tourism district}

Griboedova Canal and Dotombori Canal were selected as representative examples in the tourism district of Saint Petersburg and Osaka respectively (Photos 1). In these districts, sightseeing boats shuttle along the canals, and tourists enjoy the townscape and waterscape on the banks from the boat with a lower viewpoint than ground level. With respect to the difference between the canals of the two cities, Griboedova Canal has a constant space on both sides between the bank and buildings where tourists and vehicles can pass. Dotombori Canal on the other hand has no such space as the buildings extend to its banks, and temporary pedestrian walkways are provided along both banks. However, in terms of the distance between the water surface of Dotombori Canal and tourists, it is closer than that of Griboedova Canal.

Considering the use of waterfront spaces in the case of the two canals from the perspective of ecosystem services, the canal water and its underwater life provide an intangible service to relieve the mental stress of tourists. At the same time, tourists apprehend the improvement of water quality and habitat of the underwater life. This will result in tourist's requesting a maintainer for the canal through the Internet or other means, and the

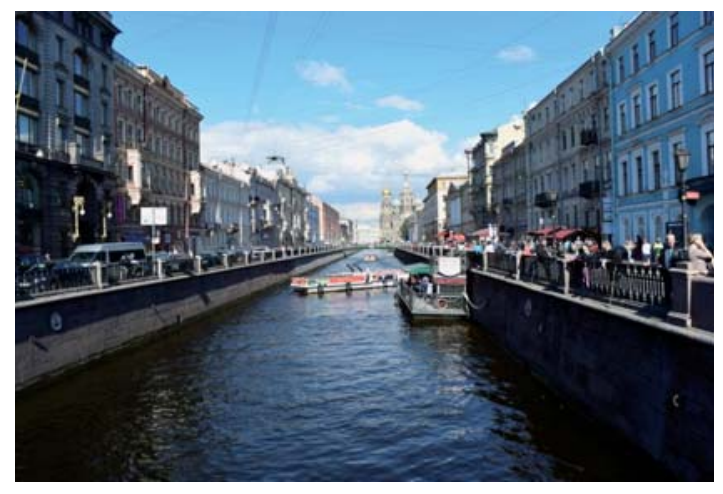

Griboedova Canal maintainer, in response, will act upon the ecosystem. In this way, an interaction between the ecosystem and humankind is generated.

\subsection{Waterfront use in the city centre}

A part of Griboedova Canal, downstream from Lion Bridge, and a part of the Dojima River, close to the business quarter were selected as representative examples in the city centre (Photos 2). In these areas, sightseeing boats and pleasure boats shuttle along the rivers and canals, and tourists as well as citizens enjoy the cityscape from the boats. As mentioned above, Griboedova Canal has a constant space between the banks and buildings facing the canal which is designed to allow people and vehicles to pass. While the Dojima River has a pedestrian walkway in some sections on both banks. A road was also built along the Dojima River in some parts, but one cannot see the river from the road. In addition, an urban motorway was constructed above and along the Dojima River which spoils the cityscape, and affects the environment of the river's ecosystem.

With respect to the use of waterfront spaces of the canal and river, having roadside trees along its banks, Griboedova Canal has an apparent ecosystem comprised of water, underwater life and vegetation. Buildings with uniform heights also stand along the canal. As an ecosystem is created in such a way, a cultural landscape service is provided here. On the other hand, in the case of the Dojima River, with the urban motorway running along it, and the height of buildings being inconsistent, it provides no cultural landscape service. This is due to the priority placed on intensive land use, and it will be essential in the future to act upon its ecosystem to create ecosystem services by for example increasing the number of trees.

\subsection{Waterfront use in the district near the mouth of the river}

The Fontanki River and Tosabori River were selected as representative examples in the district

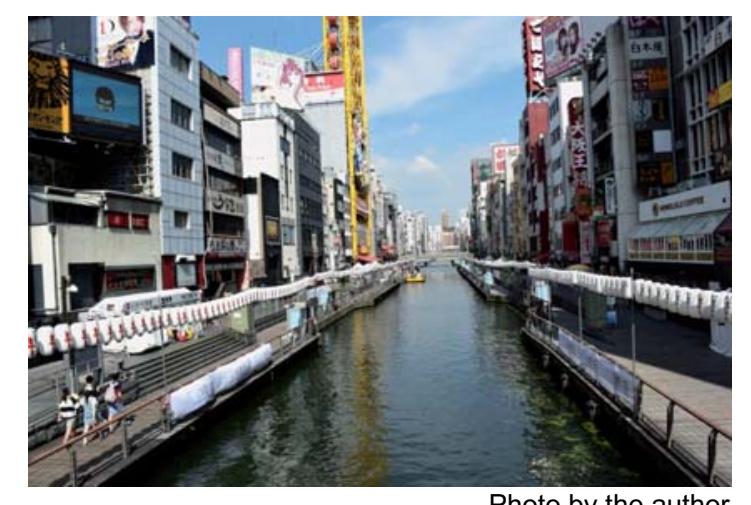

Dotombori Canal
Photo by the author

Photos 1. Waterfront use in the tourism district 


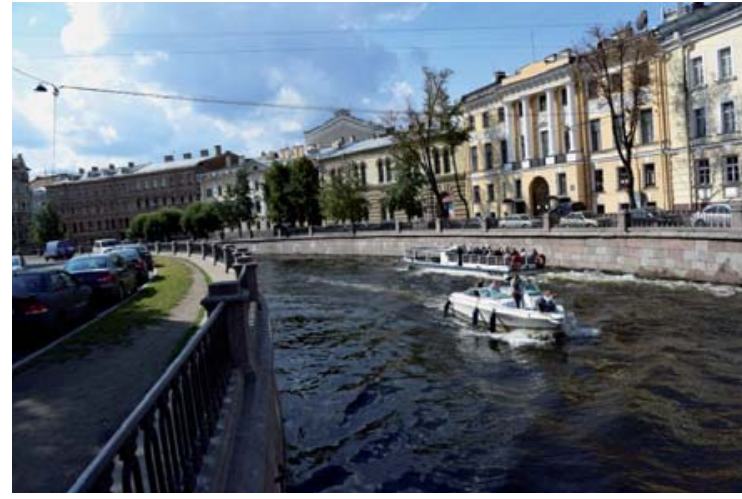

Photo by the autho

\section{Griboedova Canal}

Photos 2 . Waterfront use in the city centre

near the mouth of the river (Photos 3 ). In these districts, one finds small transport boats going by and mooring as they are near the sea. The Fontanki River has business related and residential buildings on both its banks. Likewise the Tosabori River has such a mix of buildings, except there are more highrises compared with the Fontanki River. On the banks of the Fontanki River, there are not only roads for people and vehicles but also docks where people can access and have direct contact with river water. On the other hand, the Tosabori River has no docks and people can only enjoy the view of water from the road. This is because of the high revetment built for flood prevention.

In the case of the Fontanki River, people can benefit from ecosystem services directly from the river, as they have access to it, while in the case of the Tosabori River, people indirectly benefit from ecosystem services as all they can do is to view the river. However, as such indirect ecosystem services can also be beneficial to those living in high-rises on both sides of the river, its services are wider ranging. In the future, the Tosabori River should be improved so that people can have access to it, and directly benefit from its ecosystem services.

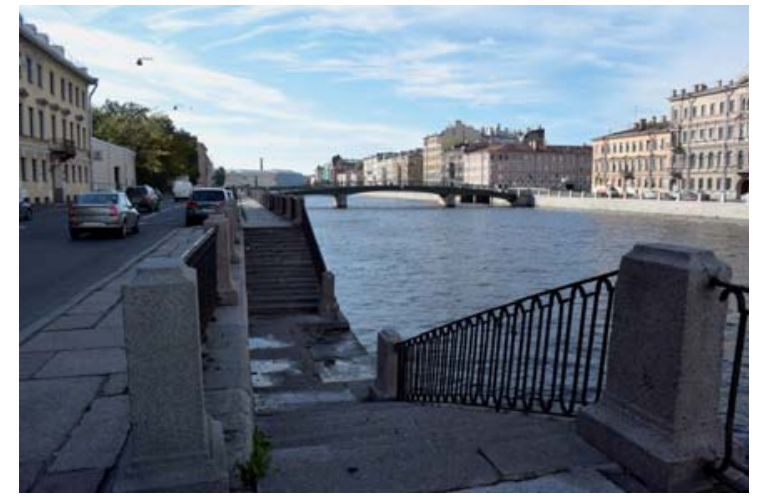

Fontanki River

Photo by the author

Photos 3. Waterfront use in the district near the mouth of the river

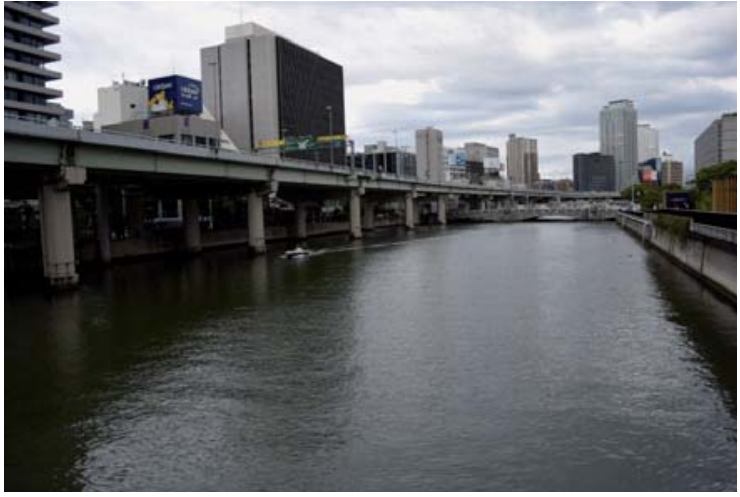

Dojima River

Photo by the author

\subsection{Waterfront use in the mouth of the river}

The Neva River and Aji River were selected as representative examples in the mouth of rivers (Photos 4). Situated in brackish-water regions, these mouths of rivers are blessed with rich ecosystems. The mouth of the Neva River enjoys a magnificent landscape with bridges connecting to historical monuments and Vasilevskiy Ostrov Island, and has heavy marine traffic with tourist boats and cargo vessels. On the other hand, at the mouth of the Aji River, the Osaka city-run ferry connects both banks for the convenience of people's travelling, as there is no connecting bridge. It has a heavy traffic of cargo vessels as there are a large number of port related facilities on its banks. There is also tourist boat traffic as it serves as part of a tour route. It also features high-rise hotels built in connection with a large-scale theme park, Universal Studios Japan, and high-rise apartment buildings.

In the case of the Neva River, people can benefit from ecosystem services from short and long distance views centred on the Neva River, from either its banks or tourist boats. For this purpose, there are many jetties for tourist boats on the banks

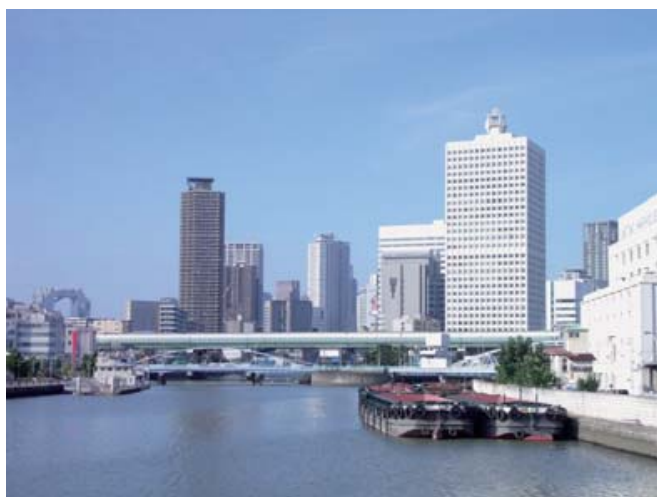

Tosabori River
Photo by the author 
and lots of tourists enjoy the tour around the mouth of the river, while benefitting from ecosystem services. In the case of the Aji River, people likewise enjoy, except that they can experience ecosystem services of the river more closely from the ferry crossing the river. Also, the guests of high-rise hotels and residents of high-rise apartments indirectly benefit from ecosystem services afforded by the spectacular views from where they stay or live. Taking advantage of the fact that the mouths of both the Neva River and Aji River are situated in an ecologically diverse brackish-water region, it will be important to actively promote water quality improvement, greening and the provision of places to make contact with the rivers, thereby allowing people to directly benefit from quality ecosystem services.

\subsection{Summary}

As above, waterfront use in Saint Petersburg and Osaka, as the study subjects, was qualitatively analyzed and considered from the perspective of ecosystem services. A summary of the results obtained through these considerations is as follows:

Firstly, the rivers and canals in Saint Petersburg retained stone banks and docks in a condition close to the original. In Osaka, they were also retained, but steel and concrete were widely used, resulting in a rather flat and not ecofriendly structure.

Secondly, the rivers and canals in Saint Petersburg have little impact from motorization, while in Osaka, several canals were filled and turned into roads due to motorization. As a result, places for the ecosystem were destroyed, thus losing the possibility of benefitting from its services, which in the end accelerated the city becoming more artificial.

Thirdly, in Saint Petersburg, there are pavements and roads between rivers/canals and buildings, while in Osaka there are no pavements or roads as buildings extend to the banks of rivers and canals. Currently pedestrian walkways are constructed on the river banks or canals, in order to benefit from their ecosystem services.

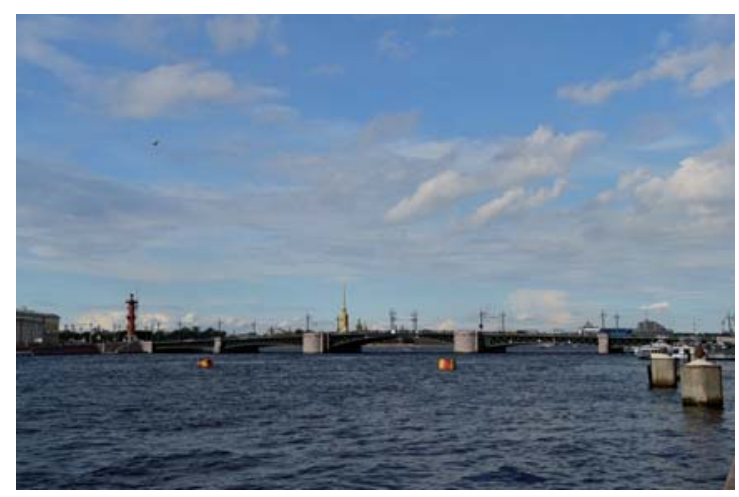

Neva River
Fourthly, the rivers and canals in Saint Petersburg are accessible for people to make contact with the water, while in Osaka, entry to rivers and canals is limited to prevent people from having accidents through contact with the water. This at the same time reduces an opportunity for people to benefit from ecosystem services and negatively impacts on people's approach toward rivers and canals.

Fifthly, it is essential to regard and plan the use of waterfront spaces from a comprehensive viewpoint. To this end, it is vital to review such spaces in relation to tangible and intangible ecosystem services and to quantify such relations.

\section{Conclusion and tasks}

The use of waterfront spaces is an important study subject for urban design and planning. However it has been predominately planned based on design elements such as form, colour and relative distance between waterfront and buildings. When recalling the fact that humankind is a part of the ecosystem, one has to take an integrated view of the use of waterfront spaces by giving deep consideration to the tangible and intangible relationship with the ecosystem. Waterfronts are valuable legacies as ecological spaces with the unity and continuity found in large cities. The effective use of such spaces represents an important issue with respect to the sustainability of metropolises.

In this study, qualitative comparative analyses and consideration were carried out from the viewpoint of ecosystem services on the present rivers and canals of Saint Petersburg and Osaka. This paper suggests the quantitative and qualitative significance of ecosystem services in order to enhance the attractiveness of the use of waterfronts. In addition to increasing the appeal of tourism resources, this can include contributions to an increase of environmental value and the incidental rise of economic value of real estate assets, reduction of public health and medical expense such as relief of mental stress and prevention of sickness.

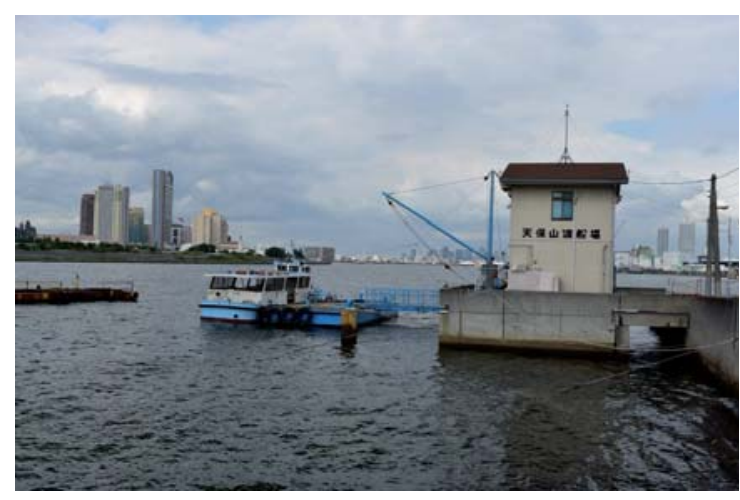

Aji River
Photo by the author

Photos 4. Waterfront use in the mouth of the river 


\section{Architecture and Engineering Volume 1 Issue 1}

As for key future tasks, it will be necessary to advance experimental studies which enable more concrete analyses, by quantifying ecosystem services related to the use of waterfronts, while for example studying the introduction of indices. Furthermore, ecosystem services involve not only the ecosystems of rivers and canals in cities, but also for example Neva Bay and Osaka Bay. What one can do to solve this is to expand the scope of spaces covered, while specifically clarifying ecosystem services related to the use of waterfronts including seashores, that is to say, the relationship between ecosystem services and humankind.

\section{References}

Millennium Ecosystem Assessment (Ed.). Ecosystems and Human Well-Being: Synthesis (21st Century COE Translation Committee, Yokohama National University. Trans.) (2011). Ohmsha, Ltd.

Odum, E. P. (1974). Ecology (Mizuno, T, trans.). Tsukiji Shokan Publishing Co., Ltd.

Hidaka, T. (Ed.). (2010). Seibutsu Tayosei-wa Naze Taisetsuka? [Chikyu-ken series] (Why Is Diversity Important?). Showado

Osaka City Planning Bureau (2005). Osaka-shi Sogo Keikaku (Osaka City's Comprehensive Plan)

Yokouchi, N. \& Yokouchi Laboratory (1988). (Eds.). Uotafuronto Kaihatsu-no Shuho (Methods for Waterfront Development). Kajima Institute Publishing Co., Ltd.

Yokouchi, N. \& Waterfront Planning Study Group (1994) (Eds.). Uotafuronto-no Keikaku Noto (Waterfront Planning Notes). Kyoritsu Shuppan Co., Ltd.

Karmazinov F.V. (ed) (2003). Vodosnabzheniye Sankt-Pyetyerburga (Water Saint Petersburg). Novyj Zhurnal, p. 591 (In Russian)

Yelisyeyeva I.I. (2001) Sankt-Pyetyerburg 1703-2003 (Saint Petersburg 1703-2003), $1^{\text {st }}$ edition, Sankt-Pyetyerburg Sudostroyeniye, pp. 9-12 (In Russian)

Committee for New Edition of the History of Osaka City (1992). Shinshu Osaka Shi (New Edition of the History of Osaka City) (Vol. 8). Osaka City, p. 105.

Committee for New Edition of the History of Osaka City (1994). Shinshu Osaka Shi (New Edition of the History of Osaka City) (Vol. 6). Osaka City, pp. 416-417.

Osaka City Environment Bureau (2003). Osaka-shi Kankyo Hakusho (Osaka City Environmental White Paper), pp. 101-110

Osaka City Planning Bureau (1991). Osaka-no Machi-zukuri--Kino/Kyo/Asu (Osaka's City Development-- Yesterday/ Today/Tomorrow), pp. 15-19, p. 119, pp. 217-219.

URL: http://www.millenniumassessment.org/en/about.slideshow.aspx 